\title{
Monitoring of atmospheric gaseous and particulate polycyclic aromatic hydrocarbons in South African platinum mines utilising portable denuder sampling with analysis by thermal desorption-comprehensive gas chromatography-mass spectrometry
}

\author{
Geldenhuys $\mathrm{G}^{\mathrm{a}, \mathrm{b}}$, Rohwer ER ${ }^{\mathrm{a}}$, Naudé $\mathrm{Y}^{\mathrm{a}}$ and Forbes PBC ${ }^{\mathrm{a}^{*}}$ \\ ${ }^{a}$ Laboratory for Separation Science, Department of Chemistry, Faculty of Natural and \\ Agricultural Sciences, University of Pretoria, Lynnwood Road, Pretoria, South Africa, 0002 \\ ${ }^{\mathrm{b}}$ Mineral Processing Laboratory, Impala Platinum Limited, 123 Bethlehem Drive, Rustenburg, \\ South Africa, 0299 \\ *Corresponding author, Tel +27 12 4205426, patricia.forbes@up.ac.za
}

\begin{abstract}
Concentrations of diesel particulate matter and polycyclic aromatic hydrocarbons (PAHs) in platinum mine environments are likely to be higher than in ambient air due to the use of diesel machinery in confined environments. Airborne PAHs may be present in gaseous or particle phases each of which has different human health impacts due to their ultimate fate in the body. Here we report on the simultaneous sampling of both phases of airborne PAHs for the first time in underground platinum mines in South Africa, which was made possible by employing small, portable denuder sampling devices consisting of two polydimethylsiloxane (PDMS) multichannel traps connected in series separated by a quartz fibre filter, which only require small, battery operated portable personal sampling pumps for air sampling. Thermal desorption coupled with comprehensive gas chromatography - mass spectrometry (TD-GCxGC-TofMS) was used to analyse denuder samples taken in three different platinum mines. The samples from a range of underground environments revealed that PAHs were predominantly found in the gas phase with naphthalene and mono-methylated naphthalene derivatives being detected at the highest concentrations ranging from 0.01 to $18 \mu \mathrm{g} \mathrm{m}^{-3}$. The particle bound PAHs were found in the highest concentrations at the idling load haul dump vehicle exhausts with a dominance of fluoranthene and pyrene. Particle associated PAH concentrations ranged from 0.47 to $260 \mathrm{ng}$ $\mathrm{m}^{-3}$ and included benzo[k]fluoranthene, benzo[a]pyrene, indeno[1,2,3-cd]pyrene and benzo[ghi]perylene. This work highlights the need to characterise both phases in order to assess occupational exposure to PAHs in this challenging sampling environment.
\end{abstract}

Keywords: polycyclic aromatic hydrocarbons; denuder; diesel exhaust emissions; diesel particulate matter; underground platinum mines; polydimethylsiloxane

\section{Introduction}

Diesel engines are widely used in industrial sectors such as transportation, mining and construction due to their high power output. Diesel exhaust emissions (DEE) are a mixture of gaseous and particulate substances originating from unburned fuel, lubricant oil and combustion products [1]. The main constituents of diesel particulate matter (DPM) are elemental carbon $(E C)$ and organic carbon $(\mathrm{OC})$. The $\mathrm{OC}$ fraction contains trace concentrations of polycyclic 
aromatic hydrocarbons (PAHs) and their methylated, nitrated and oxygenated derivatives [1]. Diesel engine PAH emissions originate from high temperature combustion of the diesel (pyrosynthesis), as well as from unburned fuel and lubricating oil [2]. Phenanthrene, fluoranthene and pyrene have thus been used as diesel markers [3].

The mining industry is a major sector of the South African economy, making significant contributions to employment numbers, export earnings, and the gross domestic product [4]. In confined environments where heavy duty diesel powered vehicles serve as sources of PAHs, such as in underground platinum mines, concentrations of DPM and PAHs are likely to be higher than in ambient air. In South Africa there are no occupational limits for PAHs. Exposure to DPM has been linked to an array of respiratory and allergic diseases [5] and DEE has recently been confirmed as carcinogenic [6] which is why the health of underground workers is of concern.

PAHs are ubiquitous environmental pollutants, which may be present both in the gaseous phase and adsorbed onto the surface of particles. It is imperative to quantify the relative contributions of each of these phases to the overall PAH profiles, as they may have different environmental as well as human health impacts, due to the fact that deposition and uptake of inhaled toxic species depends on phase distribution [7]. In a study of PAHs in a traffic tunnel in Hong Kong, for example, naphthalene, acenaphthylene, and acenaphthene were the most abundant gas phase PAHs while fluoranthene and pyrene were the most abundant in the particle phase [3]. Fushimi et al. developed a highly sensitive method for the determination of PAHs and their derivatives in trace particulate samples using thermal desorption followed by comprehensive gas chromatography coupled with tandem mass spectrometry (TD-GCxGC-MS/MS). The major analytes thus determined in diesel exhaust were phenanthene, fluoranthene, pyrene, anthracene, benz[a]anthracene, chrysene, benzo $[b]$ and $[k] f$ luoranthenes, benzo[a]pyrene, dibenzo[ah]anthracene, indeno[1,2,3-cd]pyrene and benzo[ghi]perylene [8]. Similarly, TD-GCMS has been used to determine particle phase PAHs in the indoor air of French dwellings, where $\mathrm{pg} \mathrm{m}^{-3}$ levels of benzo[a]pyrene, fluoranthene, phenanthrene and pyrene were found [9], whilst low $\mathrm{ng} \mathrm{m}^{-3}$ levels of particle phase PAHs were found in ambient air in Spain using this analytical approach [10]. Thermal desorption has the advantages of not requiring the use of organic extraction solvents and being time efficient. In addition, detection limits are improved as the entire sample (analytes) can be transferred to the GC-MS for analysis. Incomplete desorption of heavier analytes, may however counteract this, and the method is not suitable for analytes of low thermal stability [9]. Readers are referred to review articles on analytical methods for PAHs in airborne particulates and in air for more information on the various techniques available and their advantages and disadvantages [11], [12].

Conventional partitioning methods for gas and particle phase atmospheric analyte sampling are typically based on high volume samplers containing a glass fibre filter, which removes particles from the sample flow prior to adsorption of the gas phase analytes onto a downstream adsorbent such as Tenax, or polyurethane foam (PUF). For example, fifteen priority PAHs were measured in ambient air in two rural communities located several hundred km northwest of Los Angeles, and in four urban communities 40 to $100 \mathrm{~km}$ downwind of Los Angeles where particulate and vapour phase PAHs were collected on quartz fibre filters and PUF-XAD-4 resin, respectively, at $113 \mathrm{~L} \mathrm{~min}^{-1}$ for $24 \mathrm{hr}$, with quantitation by HPLC with fluorescence detection [13]. These conventional partitioning measurements based on high volume samplers may introduce analytical artifacts and under- or over-estimation of human exposure to PAHs may result from 
adsorptive and blow off effects occurring on the filter [14]. The setup required is also not suitable for underground monitoring environments as it is heavy, large and requires a source of electricity.

Denuders are sampling devices which have been effectively employed in atmospheric partitioning applications. Separation in denuders is achieved as a result of gas phase analytes having high diffusion coefficients, thus they are retained by a sorptive surface perpendicular to the gas flow (typically on the walls of the denuder). Particles, on the other hand, pass through the denuder, and can be collected on a downstream filter. A sorbent is employed behind the filter, to trap analytes desorbed from the filter, and any gaseous analytes not effectively removed by the denuder (under breakthrough conditions). Possanzini et al. tested an XAD-4 coated glass denuder for the sampling of gas phase PAHs, in conjunction with a quartz fibre filter for particle collection. The collection efficiencies of two-ring and three-ring PAHs were found to exceed $90 \%$ when a flow rate of $6 \mathrm{~L} \mathrm{~min}^{-1}$ was employed for $6 \mathrm{hr}$ [15]. Crushed Amberlite XAD-4 styrene-divinylbenzene polymer resin has also been employed in PAH denuder applications [16], [17], [7] and in another study, a high-volume compound annular denuder (consisting of a series of 12 nested denuders, $0.20 \mathrm{~m}$ long with an overall outer diameter of $80 \mathrm{~mm}$ ) was developed for the collection of PAH vapour, which utilized high-vacuum silicone grease as a sorptive medium [18], [19].

The portable denuder device that was employed in this study consisted of two multi-channel polydimethylsiloxane (PDMS) rubber traps in series separated by a quartz fibre filter, where the PDMS serves as an absorbent for gaseous semi-volatile organic compounds (SVOCs) and the filter collects particle phase analytes. The efficiency of these novel denuder devices has been investigated from both theoretical and experimental perspectives and they have been utilised in a number of applications including household fire emissions, sugar cane burning emissions and in tunnel air pollution studies [20], [21].

Here we test the application of this portable denuder in simultaneously providing gas and particle phase PAH levels in underground mining environments in South Africa for the first time. Currently no gas phase sampling is done (only the particle phase is sampled for organic and elemental carbon content). This is partly because commercial sampling devices for this type of sampling are large devices which are difficult to utilise in such space constrained locations. They also require large air volumes, necessitating heavy duty high volume sampling pumps, which are impractical for underground mining environments and additionally may have safety issues in terms of fire ignition hazards. Our method is not subject to these detracting features. A preliminary survey was therefore conducted to evaluate airborne $\mathrm{PAH}$ levels in different areas of three platinum mines in shafts where diesel engines were used (diesel shafts) as well as in those where diesel engines are not used (non-diesel) for source characterisation purposes. The gas and particle phase $\mathrm{PAH}$ concentration profiles were compared after thermal desorption coupled with comprehensive gas chromatography - mass spectrometric analysis (TD-GCxGCTofMS) of the individual denuder components (primary trap, filter and secondary trap respectively). Principal component analysis (PCA) was then performed on the dataset to identify parameters contributing to the similarity and differences between samples and denuder components. 


\section{Experimental}

\subsection{Sampling setup}

Air samples were collected by means of portable, battery operated personal sampling pumps (Sensidyne Gilair 3, Envirocon, South Africa), which are intrinsically safe for use in underground mining environments. The pumps were attached to the denuders via Tygon silicone tubing and

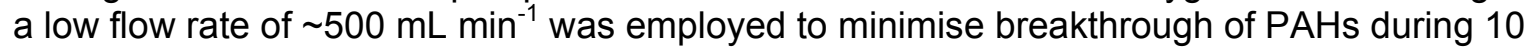
min sampling intervals. Results were normalised with respect to sample volume to take into account any differences in sampling flow rate and time. The denuder consisted of two multichannel silicone rubber traps (each trap: $178 \mathrm{~mm}$ long glass tube, $6 \mathrm{~mm}$ o.d.) each containing 22 parallel PDMS tubes $(55 \mathrm{~mm}$ long, $0.3 \mathrm{~mm}$ i.d., $0.6 \mathrm{~mm}$ o.d. Sil-Tec, Technical Products, Georgia, USA) separated by a quartz fibre filter ( $6 \mathrm{~mm}$ diameter punched from QMA $20.3 \times 25.4$ $\mathrm{cm}$, GE Healthcare, UK), which was held in position by a Teflon connector (Fig. 1). The PDMS traps were prepared according to the method described in Ortner and Rohwer [22] and the denuder was also assembled in our laboratory. Traps were end-capped with glass stoppers to prevent analyte loss and they were wrapped in aluminium foil after sampling. Filter punches inside the Teflon connectors were placed into amber glass vials post sampling. All samples were refrigerated at $-18^{\circ} \mathrm{C}$ prior to analysis. The ambient temperature at each sampling site was recorded using a Kestrel 4500 pocket weather tracker.

\subsection{Sampling sites}

The sampling campaign was undertaken during the months of July to September 2012. Samples were taken in shafts of three underground platinum mines (Plat mine A, B and C) in the North West Province of South Africa, where diesel vehicles were used (termed diesel shafts) as well as shafts that contained no diesel vehicles where conventional mining practices were being employed (termed non-diesel shafts). The samples from the diesel shafts included: ambient samples from a general mining area (both $10 \mathrm{~min}$ and 30 min sampling periods), ambient samples from within a workshop (10 $\mathrm{min}$ ) and diesel vehicle exhaust samples (10 min) from idling Load Haul Dump (LHD) trackless diesel vehicles. The underground workshops are areas where machinery, including diesel vehicles, is serviced and maintained. The general mining areas were characterized by a widely fluctuating presence of diesel vehicles, which continuously entered and left the area. The diesel exhaust samples were collected $0.5 \mathrm{~m}$ from the exhaust pipe outlet of the idling LHD vehicles (Fig. 2), which have no exhaust gas aftertreatment systems. These vehicles are used to transport mined material from the mining face to conveyor belts for transport to the surface. The longer sampling interval (30 min) was employed in order to enhance the pre-concentration and thereby the detection of the heavier PAHs, which are typically present at lower concentrations, as a larger sampling volume was then employed. In this case, breakthrough conditions of the PDMS traps would be exceeded for the more volatile PAHs (such as naphthalene), which would then be collected on the downstream, secondary PDMS trap. The non-diesel shaft sample consisted of a $10 \mathrm{~min}$ ambient sample taken from a general working area. In the case of the non-diesel shaft sample from Plat mine B, a larger sampling volume $(22 \mathrm{~L})$ was used to pre-concentrate any heavier PAHs present. The sample name and numbering protocol employed is provided in Table 1.

\subsection{Matrix matched calibration standards}

A mixed standard solution of the target PAHs $\left(2000 \mu \mathrm{g} \mathrm{m}^{-1}\right.$ in $50: 50 \mathrm{C}_{6} \mathrm{H}_{6}: \mathrm{CH}_{2} \mathrm{Cl}_{2}$, Supelco polynuclear aromatic hydrocarbons mix standard $47543-U$ ) was used for calibration purposes 
Table 1: Sample descriptions including name, abbreviations, locations and corresponding numbers, as well as the ambient temperature at each sampling location during sampling.

\begin{tabular}{llcc}
\hline \multicolumn{1}{c}{ Sample Description } & Abbreviation & $\begin{array}{c}\text { Number } \\
\text { 30 min ambient sample from Plat mine A }\end{array}$ & $\begin{array}{c}\text { Ambient } \\
\text { temperature } \\
\left({ }^{\circ} \text { C) }\right.\end{array}$ \\
\hline 30 min ambient sample from Plat mine B & 30MIN A & 1 & 31.4 \\
30 min ambient sample from Plat mine C & 30MIN B & 2 & 23.2 \\
Workshop sample from Plat mine A & WS A & 3 & 25.2 \\
Workshop sample from Plat mine B & WS B & 5 & 27.3 \\
Workshop sample from Plat mine C & WS C & 6 & 20.4 \\
LHD sample from Plat mine A & LHD A & 7 & 22.8 \\
LHD sample from Plat mine B & LHD B & 8 & 27.3 \\
LHD sample from Plat mine C & LHD C & 9 & 23.2 \\
10 min ambient sample from Plat mine A & 10MIN A & 10 & 31.4 \\
10 min ambient sample from Plat mine B & 10MIN B & $11^{\#}$ & - \\
10 min ambient sample from Plat mine C & 10MIN C & 12 & 22.3 \\
Non-diesel sample from Plat mine A & ND A & 13 & 30.9 \\
Non-diesel sample from Plat mine B & ND B & 14 & 23.2 \\
\hline
\end{tabular}

\# Not sampled due to sampling equipment constraints. LHD = Load Haul Dump vehicle. 
Figure 1: Denuder sampling setup used in the underground platinum mines

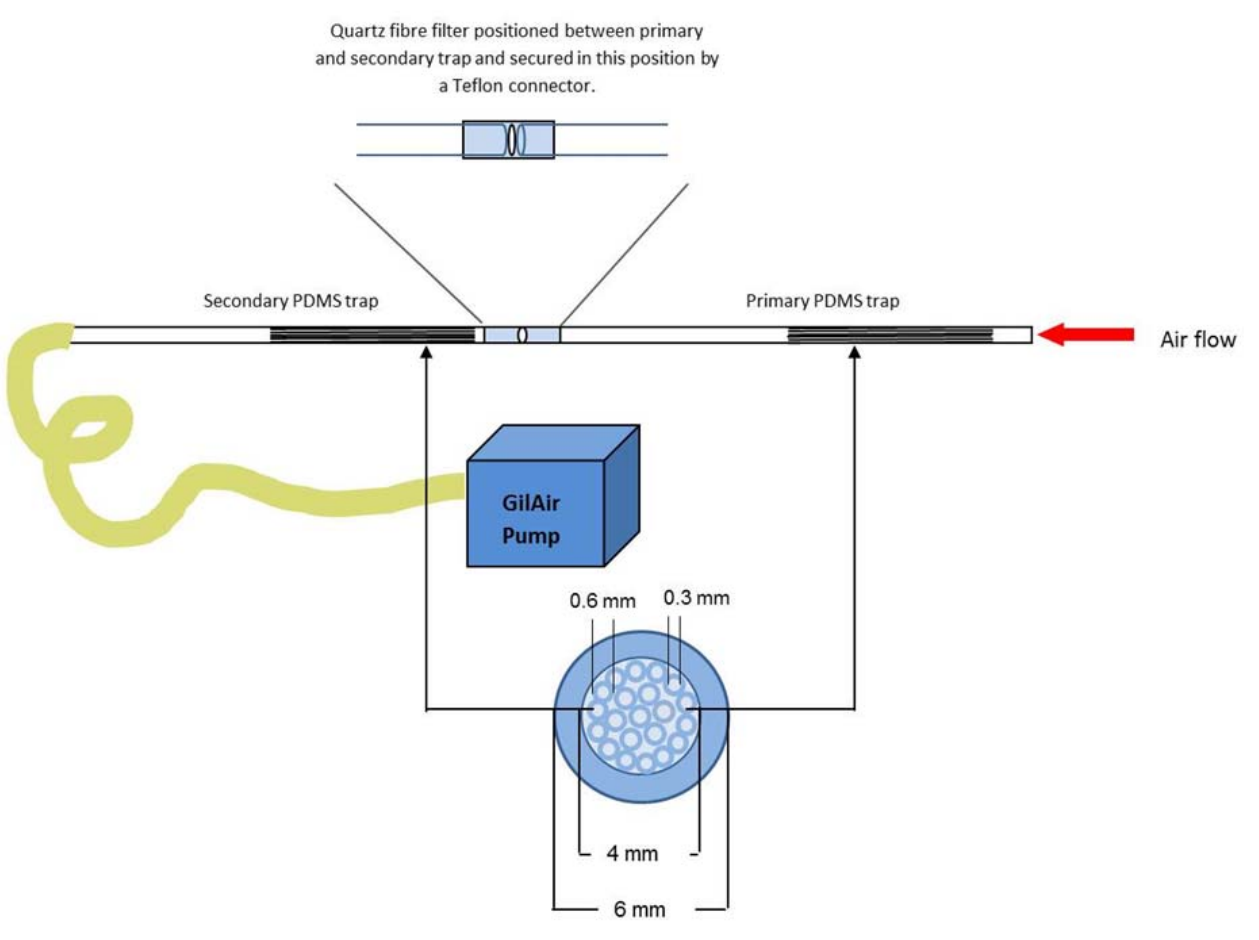


Table 2: List of PAHs detected in the samples in order of increasing molar mass and their corresponding abbreviations

\begin{tabular}{|c|c|c|}
\hline Name of $\mathrm{PAH}$ & Abbreviaton & $\begin{array}{c}\text { Molar mass } \\
\left(\text { g.mol }{ }^{1-}\right)\end{array}$ \\
\hline Azulene & $\mathrm{AZU}$ & 128 \\
\hline Naphthalene & NAP & 128 \\
\hline Naphthalene, 2-methyl- & NAP $2 M$ & 142 \\
\hline Naphthalene, 1-methyl- & NAP $1 \mathrm{M}$ & 142 \\
\hline Acenaphthylene & ACY & 152 \\
\hline Acenaphthene & ACE & 154 \\
\hline Fluorene & FLU & 166 \\
\hline 1H-Phenalene & 1HPHA & 166 \\
\hline Phenanthrene & PHE & 178 \\
\hline Anthracene & ANT & 178 \\
\hline Fluoranthene & FLA & 202 \\
\hline Pyrene & PYR & 202 \\
\hline 11H-Benzo[a]fluorene & $11 \mathrm{HBaF}$ & 216 \\
\hline 7H-Benzo[b]fluorene & $7 \mathrm{HBbF}$ & 216 \\
\hline Benzo[ghi]fluoranthene & BghiF & 226 \\
\hline Benz[a]anthracene & $\mathrm{BaA}$ & 228 \\
\hline Chrysene & $\mathrm{CHY}$ & 228 \\
\hline Perylene & PER & 252 \\
\hline Benzo[b]fluoranthene & $\mathrm{BbF}$ & 252 \\
\hline Benzo[k]fluoranthene & $\mathrm{BkF}$ & 252 \\
\hline Benzo[]]fluoranthene & $\mathrm{BjF}$ & 252 \\
\hline Benzo[a]pyrene & $\mathrm{BaP}$ & 252 \\
\hline Benzo[e]pyrene & $\mathrm{BeP}$ & 252 \\
\hline Indeno[1,2,3-cd]pyrene & I123P & 276 \\
\hline Benzo[ghi]perylene & BghiP & 276 \\
\hline Dibenz[ah]anthracene & DbahA & 278 \\
\hline
\end{tabular}


(refer to Table 2 for the PAH abbreviations employed). Matrix matched calibration curves were generated in order to quantify PAHs sampled onto traps by analysing individual conditioned PDMS traps that were spiked with one $\mu \mathrm{L}$ of $0.1,1.0,5.0$ or $10.0 \mathrm{ng}^{-1} \mathrm{~L}^{-1}$ mixed PAH standards in toluene, respectively. Punches of a loaded $35 \mathrm{~mm}$ personal sampling filter (representing the DPM matrix) was spiked with one $\mu \mathrm{L}$ of $0,0.001,0.01,0.1,0.5$ or $1.0 \mathrm{ng} \mu \mathrm{L}^{-1}$ mixed PAH standards in toluene, respectively, in order to quantify particle bound PAHs sampled onto the filter. Linear regression analyses were performed after blank correction, using the Data Analysis Toolkit in Excel. The limit of detection (LOD) of each target compound was calculated as three times the signal to noise (S/N) ratio and the limit of quantitation (LOQ) as ten times the S/N ratio [23]. The use of matrix matched standards for calibration purposes was necessary in order to correct for any reduced recoveries for heavier PAHs.

\subsection{Instrumental analysis}

The TD-GCxGC-TofMS employed was a Pegasus 4D system (Leco, St. Joseph, MI, USA), equipped with an Agilent Technologies 6890 GC (Palo Alto, CA, USA). A Gerstel 3 thermal desorber system (TDS) operated in splitless mode allowed for sample introduction, where each individual primary and secondary trap was thermally desorbed directly and each filter was positioned in the heated zone of an empty glass thermal desorption tube for analysis. Data acquisition and processing was carried out using ChromaTOF software version 4.0 (LECO, St. Joseph, MI, USA). The GC inlet was in the solvent vent mode with helium (Ultra High Purity, Afrox) as the inlet gas. The GC column set consisted of a Rxi-5Sil, 5\%-phenyl-95\%methylsiloxane ( $30 \mathrm{~m}, 0.25 \mathrm{~mm}$ i.d., $0.25 \mu \mathrm{m}$ df, Restek Bellefonte, USA) in the first dimension (1D) and a Rxi-200, 50\%-phenyl-50\%-methylsiloxane (1.5 m, $0.1 \mathrm{~mm}$ i.d., $0.1 \mu \mathrm{m}$ df, Restek Bellefonte, USA) in the second dimension (2D). Thermal desorption was carried out from $30^{\circ} \mathrm{C}$ to $280^{\circ} \mathrm{C}$ (5 min hold time) at $60^{\circ} \mathrm{C} \mathrm{min}{ }^{-1}$. The desorbed SVOCs were cryogenically focused via a cooled injection system (CIS) at $-50^{\circ} \mathrm{C}$ using liquid nitrogen. A Gerstel baffled liner was employed. The temperature was rapidly ramped at $12{ }^{\circ} \mathrm{C} \mathrm{s}^{-1}$ to $280^{\circ} \mathrm{C}$ in order to introduce the analytes onto the GC column and the inlet purge time was $3 \mathrm{~min}$. The desorption flow rate was $100 \mathrm{~mL} \mathrm{~min}{ }^{-1}$ and the TDS transfer line was at $280^{\circ} \mathrm{C}$. The primary oven was ramped at $10^{\circ} \mathrm{C}$ $\mathrm{min}^{-1}$ from $40{ }^{\circ} \mathrm{C}$ to $315^{\circ} \mathrm{C}$ which was held for $5 \mathrm{~min}$. The secondary oven was offset by $+5{ }^{\circ} \mathrm{C}$ from the primary oven and the modulator temperature was offset by $30^{\circ} \mathrm{C}$ to the secondary oven temperature. The modulation period was $4 \mathrm{~s}$ with a hot pulse time of $1 \mathrm{~s}$. The MS transfer line temperature was set to $280^{\circ} \mathrm{C}$. Mass acquisition was from 50 to 500 Daltons (Da) at 100 spectra s$~^{-1}$. The electron energy was $70 \mathrm{eV}$ and the ion source temperature was $200^{\circ} \mathrm{C}$.

\subsection{Target PAHs and quality control}

The following target PAHs were determined in the samples: naphthalene, 1-methylnaphthalene, 2-methylnaphthalene, acenaphthylene, acenaphthene, fluorene, phenanthrene, fluoranthene, pyrene, benz[a]anthracene + chrysene, benzo[k]fluoranthene, benzo[a]pyrene, indeno[1,2,3$c d$ ]pyrene, and benzo[ghi]perylene. Compounds were identified based on comparison of retention times and mass spectra to that of authentic reference standards (individual PAH standards obtained from Sigma Aldrich) and of the NIST08 mass spectral library (match quality $\geq 80 \%$ ). The National Institute of Standards and Technology (NIST) 2975 DPM standard 
reference material was also used in the method development, in terms of assessing particle phase PAH desorption efficiencies.

One field blank was analysed for each mine's sample set. Blank (empty) PDMS traps and filters were also analysed. A bake out method was applied between each sample run whereby the oven temperature was set to $300{ }^{\circ} \mathrm{C}$ and the TD was baked out at $300{ }^{\circ} \mathrm{C}$ for 30 min. Blank PDMS (conditioned) traps were analysed after baking out to ensure that there was no analyte carry over between sample runs.

Principal component analysis (PCA) was performed using JMP 10 software, where the relative $\%$ peak area (peak area of PAH / total peak area for all identified SVOCs $x 100$ ) for each PAH was used.

\section{Results and Discussion}

With the denuder employed in this study, the secondary trap downstream of the filter filter is expected to capture any desorbed analytes from the particles on the filter, when operating below breakthrough volume conditions. Further detail on this denuder setup is provided in [20]. The PDMS in the multi-channel traps acts as an absorbent for semi-volatile organic compounds (including PAHs) therefore sample recovery is expected to be higher due to absorption taking place rather than adsorption. Although adsorbents such as Tenax and Chromosorb retain semivolatile analytes strongly, this often prevents rapid and complete desorption, leading to low recoveries and the risk of carryover between samples. The slow rate of desorption from these materials also may result in reactions between analytes or with the surface itself, leading to unwanted artefact formation [24]. PDMS is far more inert, has more reproducible retention of analytes, and its degradation products can easily be identified by MS [24]. An additional advantage of utilising our denuder is that the components of the denuder can be directly analysed using a commercial thermal desorption system.

The use of matrix matched standards was necessary to overcome any recovery effects [25]. In terms of the particulate samples, PAH standards were spiked onto loaded filter punches from a similar platinum underground mining environment, which were then analysed in the same manner as the samples to establish the calibration curves after correction for PAHs present in the unspiked sample. Any suppression in PAH recoveries, especially with respect to the heavier PAHs was thereby accounted for. It should also be noted that the main purpose of this study was to determine PAH profiles for the different mines and underground sampling environments in order to allow for inter-sample comparison.

\subsection{PAH quantitation}

The results of the linear regression analyses performed for trap and filter samples are shown in Table 3. The method detection limits for each PAH are also included, where LOQs ranged from 0.20 to $14 \mathrm{ng} \mathrm{m}^{-3}$ for the trap samples and from 0.20 to $3.5 \mathrm{ng} \mathrm{m}^{-3}$ for the filters. The difference between the calibration curves for the two phases is due to the influence of the matrix in the thermal desorption process, and these differences in the calibration curves indeed show the 
Table 3: Linear regression analysis results with mass and mass/volume limits of detection (LOD) and limits of quantitation (LOQ) of PAHs on traps and filters. The LOD was calculated as the concentration that gave a signal-to-noise ratio of 3 and the LOQ gave a signal-to-noise ratio of 10 . The absolute minimum detector limit for the TofMS was taken as $1 \mathrm{pg}$.

\begin{tabular}{|c|c|c|c|c|c|c|c|}
\hline $\mathrm{PAH}$ & $\begin{array}{l}\text { Quantification } \\
\text { ion } \\
\mathrm{m} / \mathrm{z}\end{array}$ & $r^{2}$ & Equation & $\begin{array}{l}\text { LOD } \\
\text { (pg) }\end{array}$ & $\begin{array}{l}\text { LOQ } \\
\text { (pg) }\end{array}$ & $\begin{array}{l}\text { LOD } \\
\left(\mathrm{ng} \mathrm{m}^{-3}\right)\end{array}$ & $\begin{array}{l}\text { LOQ } \\
\left(\mathrm{ng} \mathrm{m}^{-3}\right)\end{array}$ \\
\hline \multicolumn{8}{|l|}{ TRAPS (gas phase) } \\
\hline Naphthalene & 128 & 0.9949 & $y=1893241 x-67835$ & 1.0 & 3.3 & 0.20 & 0.67 \\
\hline 2-methylnaphthalene & 142 & 0.9953 & $y=948218 x-185685$ & 1.0 & 3.3 & 0.20 & 0.67 \\
\hline 1-methylnaphthalene & 142 & 0.9899 & $y=1079149 x-338232$ & 1.0 & 3.3 & 0.20 & 0.67 \\
\hline Acenaphthylene & 152 & 0.9975 & $y=613792 x-127873$ & 1.0 & 3.3 & 0.20 & 0.67 \\
\hline Acenaphthene & 154 & 1.0000 & $y=754548 x-17815$ & 1.0 & 3.3 & 0.20 & 0.67 \\
\hline Fluorene & 166 & 0.9863 & $y=698537 x-192547$ & 1.0 & 3.3 & 0.20 & 0.67 \\
\hline Phenanthrene & 178 & 0.9849 & $y=1260468 x-646079$ & 1.0 & 3.3 & 0.20 & 0.67 \\
\hline Fluoranthene & 202 & 0.9888 & $y=475468 x-175354$ & 1.0 & 3.3 & 0.20 & 0.67 \\
\hline Pyrene & 202 & 0.9867 & $y=541111 x-228974$ & 1.4 & 4.6 & 0.27 & 0.92 \\
\hline Chrysene+benz[a]anthracene & 228 & 0.9817 & $y=717408 x-403439$ & 1.4 & 4.8 & 0.29 & 0.95 \\
\hline Benzo[k]fluoranthene & 252 & 0.9837 & $y=636974 x-357267$ & 2.2 & 7.3 & 0.44 & 1.5 \\
\hline
\end{tabular}


Figure 2: Denuder sampling at the exhaust of an idling Load Haul Dump (LHD) diesel vehicle in an underground platinum mine.

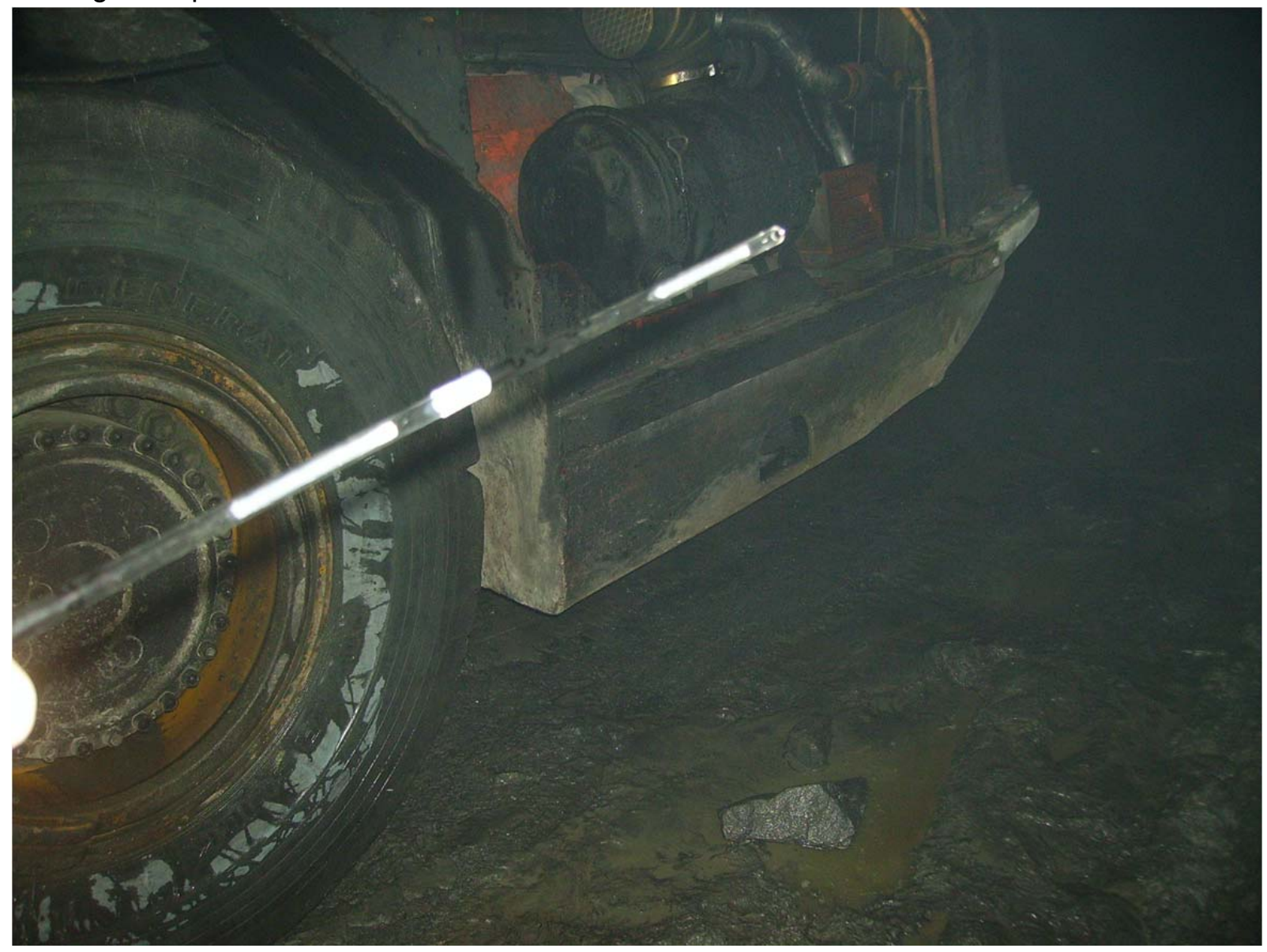

Figure 3: Contour plot of a reconstructed ion chromatogram $(128,142,152,154,166,178$, $202,228,252,276$, and $278 \mathrm{Da}$ ) of a thermally desorbed PDMS primary trap sample (gas phase) taken at a Load Haul Dump (LHD) vehicle exhaust

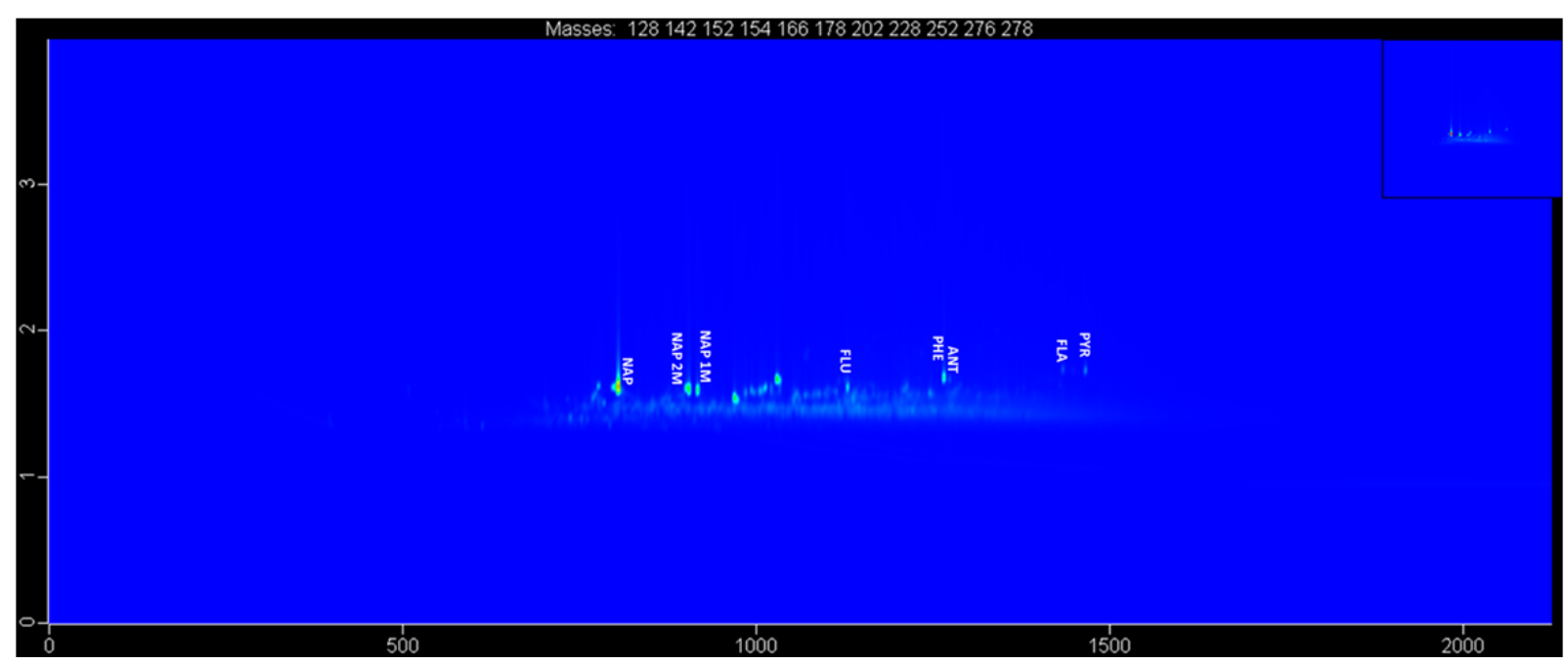


Figure 4: Contour plot of a reconstructed ion chromatogram $(128,142,152,154,166,178$, $202,228,252,276$, and $278 \mathrm{Da}$ ) of a thermally desorbed quartz fibre filter sample (particle phase) taken in an underground workshop

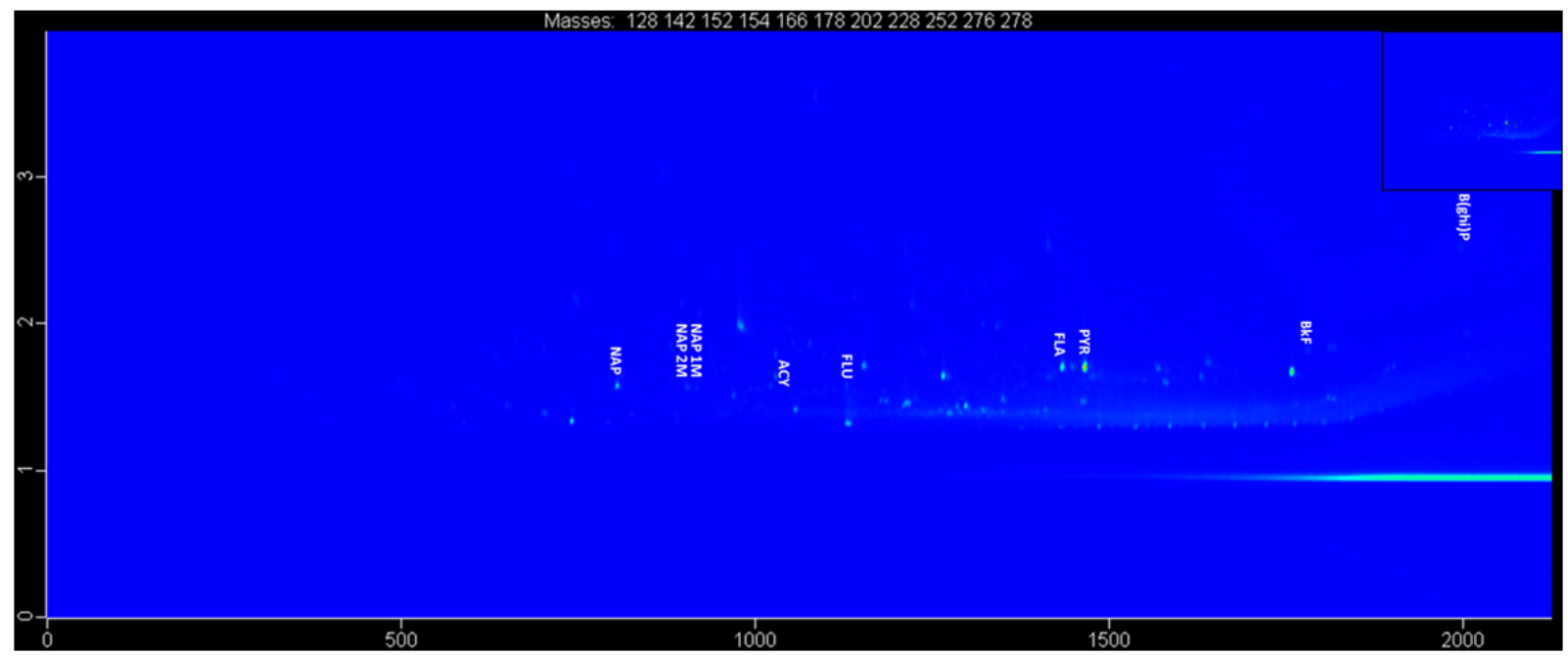

Figure 5: Bubble plots of the relative \% peak areas per litre of air sampled of gas phase PAHs found in the primary trap samples excluding sample \#14, and including sample \#14 in the insert (refer to Table 1 for sample numbers)

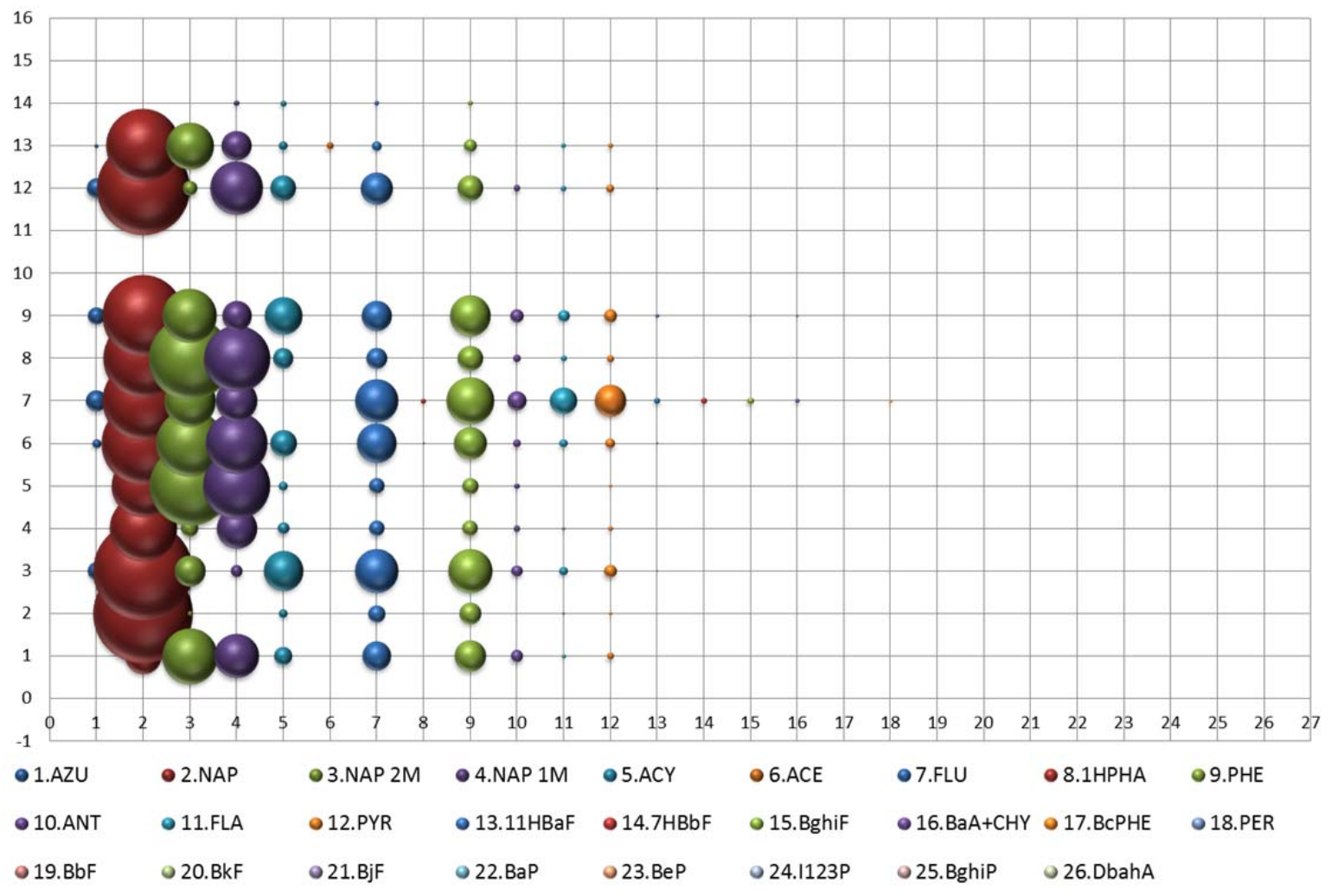


Table 4: Concentrations of PAHs found in the gas phase on the primary traps $\left(\mu \mathrm{g} \mathrm{m}^{-3}\right)$; in the particle phase on the quartz fibre filters $\left(\mathrm{ng} \mathrm{m}^{-3}\right)$ and in the secondary traps $\left(\mu \mathrm{g} \mathrm{m}^{-3}\right)$ of the denuder samplers taken in a range of underground environments.

\begin{tabular}{|c|c|c|c|c|c|c|c|c|c|c|c|c|}
\hline PAH & $\begin{array}{c}30 \mathrm{MIN} \\
\mathrm{A}\end{array}$ & $\begin{array}{c}30 \mathrm{MIN} \\
\mathrm{B}\end{array}$ & $\begin{array}{c}\text { 30MIN } \\
\mathrm{C}\end{array}$ & WS A & WS B & WS C & LHD A & $\begin{array}{c}\text { LHD } \\
\text { B }\end{array}$ & $\begin{array}{c}\text { LHD } \\
\text { C }\end{array}$ & $\begin{array}{c}10 \mathrm{MIN} \\
\mathrm{C}\end{array}$ & ND A & ND B \\
\hline \multicolumn{13}{|c|}{ PRIMARY TRAP $\left(\mu \mathrm{g} \mathrm{m}^{-3}\right)$} \\
\hline NAP & 0.15 & 0.87 & 2.1 & 2.0 & 0.48 & 4.5 & 8.7 & 1.7 & 6.7 & 4.0 & 1.3 & 18 \\
\hline NAP 2M & 0.75 & 0.01 & 0.41 & 0.29 & 1.6 & 6.0 & 7.1 & 3.6 & 6.0 & 0.20 & 1.1 & \\
\hline NAP $1 \mathrm{M}$ & 0.43 & - & 0.06 & 1.3 & 0.99 & 4.5 & 4.1 & 2.1 & 1.6 & 2.3 & 0.41 & 0.02 \\
\hline $\mathrm{ACY}$ & 0.13 & 0.02 & 1.0 & 0.22 & 0.07 & 1.4 & - & 0.34 & 4.4 & 0.92 & 0.09 & 0.03 \\
\hline ACE & - & - & - & - & - & - & - & - & - & - & 0.03 & \\
\hline FLU & 0.28 & 0.07 & 1.1 & 0.32 & 0.13 & 2.8 & 6.6 & 0.31 & 2.4 & 1.3 & 0.11 & 0.02 \\
\hline PHE & 0.21 & 0.07 & 0.62 & 0.26 & 0.15 & 1.1 & 4.5 & 0.29 & 2.6 & 0.49 & 0.16 & 0.03 \\
\hline ANT & - & - & - & - & - & - & - & - & - & - & - & - \\
\hline FLA & 0.03 & 0.01 & 0.07 & 0.09 & - & 0.21 & 3.9 & 0.06 & 0.57 & 0.09 & 0.09 & 0.02 \\
\hline PYR & 0.05 & 0.02 & 0.13 & 0.11 & 0.09 & 0.25 & 4.7 & 0.08 & 0.63 & 0.13 & 0.10 & 0.02 \\
\hline $\mathrm{BaA}+\mathrm{CHY}$ & - & - & - & - & - & - & 0.18 & - & 0.13 & - & - & - \\
\hline $\mathrm{BbF}$ & - & - & - & - & - & - & & - & - & - & - & - \\
\hline $\mathrm{BkF}$ & - & - & - & - & - & - & 0.12 & - & - & - & - & - \\
\hline $\mathrm{BjF}$ & - & - & - & - & - & - & - & - & - & - & - & - \\
\hline $\mathrm{BaP}$ & - & - & - & - & - & - & 0.14 & - & - & - & - & - \\
\hline $\mathrm{BeP}$ & - & - & - & - & - & - & - & - & - & - & - & - \\
\hline I123P & - & - & - & - & - & - & - & - & - & - & - & - \\
\hline BghiP & - & - & - & - & - & - & - & - & - & - & - & - \\
\hline \multicolumn{13}{|c|}{ FILTER $\left(n g m^{-3}\right)$} \\
\hline NAP & 2.1 & 0.96 & - & - & - & - & 6.3 & 2.4 & - & - & - & - \\
\hline NAP 2M & 2.2 & 1.3 & - & - & - & - & 5.9 & - & - & - & - & - \\
\hline NAP $1 \mathrm{M}$ & 1.8 & - & - & - & - & - & - & - & - & - & - & - \\
\hline ACY & - & - & - & - & - & - & - & - & - & - & - & - \\
\hline ACE & & & & - & - & - & - & - & - & - & - & - \\
\hline FLU & 1.1 & 0.47 & 1.1 & - & - & 3.1 & 3.1 & & 3.4 & 1.6 & - & - \\
\hline PHE & 1.7 & 1.5 & 6.6 & - & - & 9.7 & 3.2 & 0.82 & 6.0 & 3.9 & - & - \\
\hline ANT & & & & & - & & & & & & - & - \\
\hline FLA & 4.9 & 3.2 & 14 & - & - & 39 & 3.4 & 0.52 & 15 & 43 & - & - \\
\hline PYR & 17 & 6.6 & 59 & - & - & 110 & 12 & 3.6 & 39 & - & - & - \\
\hline $\mathrm{BaA}+\mathrm{CHY}$ & 2.3 & $<L O Q$ & 3.5 & - & - & 16 & 31 & 1.7 & $<L O Q$ & 6.8 & - & - \\
\hline $\mathrm{BbF}$ & - & - & - & - & - & - & - & - & - & - & - & - \\
\hline $\mathrm{BkF}$ & - & - & - & - & - & 17 & 55 & - & - & - & - & - \\
\hline $\mathrm{BjF}$ & - & - & - & - & - & - & - & - & - & - & - & - \\
\hline $\mathrm{BaP}$ & 2.1 & - & - & - & - & 34 & 128 & - & - & - & - & - \\
\hline $\mathrm{BeP}$ & & & & - & - & & & - & - & - & - & - \\
\hline I123P & - & - & - & - & - & 7.5 & 250 & - & - & - & - & - \\
\hline BghiP & - & - & - & - & - & 110 & 260 & - & - & - & - & - \\
\hline \multicolumn{13}{|c|}{ SECONDARY TRAPS $\left(\mu \mathrm{g} \mathrm{m}^{-3}\right)$} \\
\hline NAP & 0.49 & 0.43 & 1.1 & 0.08 & 0.02 & 0.60 & 4.9 & 0.18 & 2.4 & 0.62 & 0.06 & 1.3 \\
\hline NAP 2M & 0.34 & 0.45 & 0.41 & 0.06 & 0.05 & 0.28 & 0.41 & 0.11 & - & 0.16 & 0.05 & 0.17 \\
\hline
\end{tabular}




\begin{tabular}{ccccccccccccc} 
NAP 1M & 0.21 & 0.33 & - & 0.08 & 0.07 & - & 0.24 & - & 0.26 & 0.11 & 0.07 & 0.04 \\
ACY & 0.02 & 0.01 & 0.03 & - & - & 0.06 & 0.05 & 0.02 & 0.05 & 0.07 & 0.04 & 0.02 \\
ACE & - & - & - & - & - & - & - & - & - & - & - & - \\
FLU & 0.02 & 0.01 & 0.02 & - & - & 0.05 & 0.05 & 0.03 & 0.05 & 0.04 & - & 0.02 \\
PHE & 0.04 & 0.02 & 0.04 & 0.10 & - & 0.09 & 0.10 & 0.05 & 0.11 & 0.07 & - & 0.03 \\
ANT & - & - & - & - & - & - & - & - & - & - & - & - \\
FLA & 0.03 & 0.01 & 0.03 & - & - & 0.10 & 0.09 & 0.04 & 0.08 & 0.06 & - & - \\
PYR & 0.04 & 0.02 & 0.06 & - & - & 0.11 & 0.13 & 0.04 & 0.09 & 0.08 & - & 0.02 \\
\hline
\end{tabular}

“-" indicates that the analyte was <LOD.

Sample 10MIN A was not analysed due to an instrument malfunction. 
importance of using matrix matched standards for calibration purposes, as well as the need for having separate calibration curves for PDMS and filter samples, respectively.

The samples were complex, with thousands of compounds being tentatively identified by the deconvolution software. GCxGC-TofMS was therefore particularly effective for this type of analysis as it allowed for the separation of target analytes from other compounds, including PDMS degradation products, in the second dimension which co-eluted in the first dimension. This can be seen in the typical reconstructed ion chromatograms for a trap and filter sample which are shown in Figs 3 and 4.

The concentrations of PAHs found in the primary trap (gas phase PAHs), on the filter (particle phase PAHs) and on the secondary trap (PAHs which have broken through the primary trap (in the case of 30 min sampling) or may have blown off the particles collected on the filter) are presented in Table 4. Gas phase PAHs were found to be in the low $\mu \mathrm{g} \mathrm{m}^{-3}$ range $(0.01$ to $18 \mu \mathrm{g}$ $\mathrm{m}^{-3}$ ), whilst particle associated PAHs were present at $\mathrm{ng} \mathrm{m}^{-3}$ levels $\left(0.47\right.$ to $\left.260 \mathrm{ng} \mathrm{m}^{-3}\right)$. No reported airborne PAH levels in underground mining environments could be obtained from literature for comparison, although urban indoor particle phase PAH concentrations in the $\mathrm{pg} \mathrm{m}^{-3}$ range ( 7.0 to $\left.228 \mathrm{pg} \mathrm{m}^{-3}\right)$ have been reported in France [9] and from 0.002 to $0.945 \mathrm{ng} \mathrm{m}^{-3}$ in ambient urban air in Spain [10]. Gas phase PAH concentrations were found to range from 31.4 to $84.7 \mathrm{ng} \mathrm{m}^{-3}$ in urban ambient air in Greece, whilst particle phase PAHs were between 11.4 and $44.9 \mathrm{ng} \mathrm{m}^{-3}$ [26]. The concentrations of PAHs in both phases determined in this study are therefore elevated in comparison to these other environments. The results from this underground mining study will be discussed in more detail in terms of the variations in PAH concentration between sample types as well as between mines in sections 3.2 and 3.3.

\subsection{PAH profiles}

The overall PAH profiles for the denuder samples are presented as bubble plots in Figs 5 and 6 which give an indication of which PAHs were prominently detected in each phase in each of the samples. The PAHs that were detected in the gas phase samples (primary PDMS traps) were the more volatile PAHs such as naphthalene and its mono- methylated derivatives, as expected. The PAHs that were detected in the particle phase (filters) were heavier, less volatile PAHs with pyrene being the most dominant PAH present overall. The difference between the PAH fingerprints for each phase demonstrates the efficiency of the denuder sampling device in simultaneously sampling both $\mathrm{PAH}$ phases. Benzo[k]fluoranthene, benzo[a]pyrene, indeno[1,2,3-cd]pyrene and benzo[ghi]perylene were amongst the heavier PAHs that were detected in the particle phase underground. A surprisingly high level of gas phase naphthalene $\left(17.88 \mu \mathrm{g} \mathrm{m}^{-3}\right)$ was found in one of the non-diesel shaft samples, the source of which is unknown (refer to insert in Fig.5). It should be noted that a larger air volume was sampled in this case $(22 \mathrm{~L})$ in order to pre-concentrate any trace levels of heavier PAHs to allow for their detection. These were not found in this sampling environment, however, the larger sample volume did result in breakthrough of the more volatile PAHs from the primary trap.

PAHs present on the secondary traps were the most volatile PAHs and they may have originated from blow off from particles collected on the filter. Breakthrough of gaseous PAHs from the primary trap should not have occurred, except in the case of the 30 min sample, as the sampling volume was generally maintained below the $\sim 5 \mathrm{~L}$ trap breakthrough volume of the most volatile $\mathrm{PAH}$, namely naphthalene, as determined by a laser induced fluorescence measurement [27]. 
Figure 6: Bubble plots of the relative \% peak areas per litre of air sampled of particle phase PAHs found in the filter samples (refer to Table 1 for sample numbers)

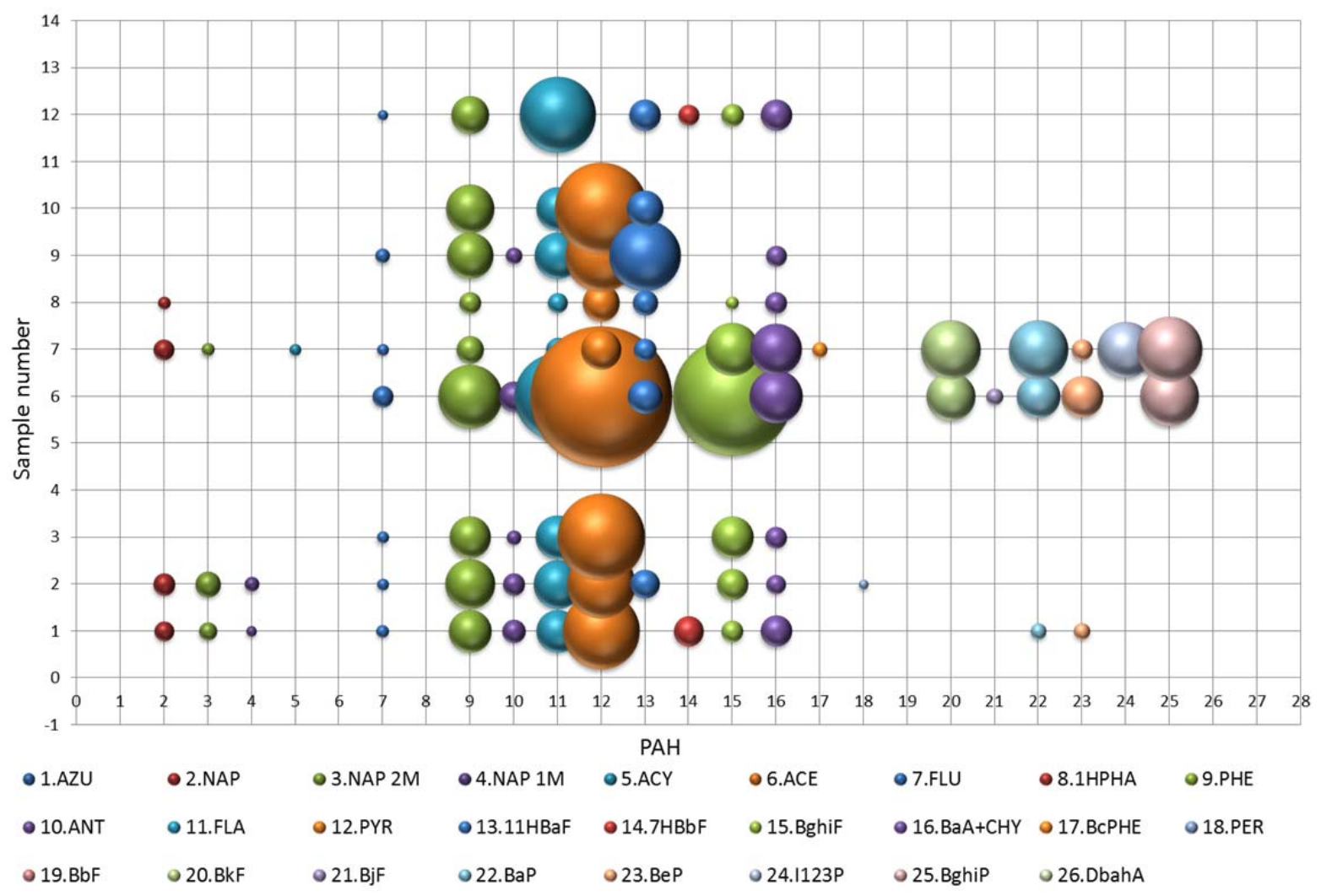


The 30 min ambient samples were taken in areas where diesel machinery was being utilized. It is evident from Table 4 that the highest concentrations for gas phase naphthalene, acenaphthylene, fluorene, phenanthrene, fluoranthene and pyrene were found in the primary trap sample from Plat Mine $C$ with the naphthalene concentration being twice as high as any other PAH. Somewhat larger and less volatile PAHs, namely fluoranthene and pyrene, were the PAHs found at highest levels associated with the particles. The Plat mine B sample had the lowest particle loading of PAHs, which was expected as during the sampling period there was not as much activity (scooping, loading and idling) of the diesel machinery as there was at the other mines. The more volatile PAHs were present on the secondary trap (naphthalene; 1methylnaphthalene and 2-methylnaphthalene), which was due to breakthrough having occurred as a result of the longer sampling interval and the associated higher sampling volume. The 10 min samples showed similar trends to the 30 min ambient samples which was expected as they were taken in the same environments. Here the breakthrough volume was not exceeded, which is evident from the significantly lower concentrations of PAHs present on the secondary trap. These PAHs may have reached the secondary trap as a result of blowoff from the particles.

The highest number and concentration of PAHs were found in the Plat mine A LHD exhaust sample that was taken at a source of diesel engine emissions. Figure 7 represents the PAH profile for this sample type, including the gas phase PAH profile (primary trap, top graph); particle phase PAH profile, (filter, middle graph) and secondary trap PAH profile (bottom graph). For LHD samples, primary trap concentrations ranged from 0.06 to $8.7 \mu \mathrm{g} \mathrm{m}^{-3}$ and particle associated PAH concentrations of between 0.52 and $260 \mathrm{ng} \mathrm{m}^{-3}$ were detected. The LHD Plat Mine A particle sample contained the heavier 5-6 ringed PAHs such as benzo[ $k$ fluoranthene, benzo[a]pyrene, indeno[1,2,3-cd]pyrene and benzo[ghi]perylene, with benzo[k]fluoranthene and benzo[a]pyrene being present at similar concentration ranges in both the gas and particle phases. Emission of these heavier PAHs was likely a consequence of the cold start conditions of the diesel vehicle sampled, which was observed during sampling. It should be noted that in addition to cold start conditions, the vehicle age, maintenance and operating conditions impact on the profiles that were obtained [2]. The LHD profiles were different to the $30 \mathrm{~min}$ and $10 \mathrm{~min}$ ambient sample profiles, in that the heavier PAHs were not detected in the ambient profiles and the concentrations were also appreciably lower. This may indicate that ventilation is adequate or that the particles with which the heavier PAHs were associated deposited rapidly after emission by dry deposition and were thus not present in the ambient air. This is encouraging from a human exposure perspective.

The workshop samples revealed that only the Plat mine $C$ filter sample contained particle phase PAHs (Table 4). Once again it must be noted that the workshop at each mine was different in terms of operational activity and the number of factors influencing results were numerous. The number and concentration of PAHs in shafts where no diesel vehicles operate were significantly less (with the exception of the high naphthalene peak that was detected at Plat mine B, the source of which requires further investigation) and no particle associated PAHs were detected, which indicates that DEE was the main source of PAHs underground.

\subsection{Partitioning of atmospheric PAHs between gas and particle phases in underground environments}

The analysis of PAH distributions between gas and particle phases revealed that significantly more PAHs were present in the gas phase as the total particle phase PAHs ranged from 9.1 to 
Figure 7: PAH concentrations found in air sampled at the exhaust of idling underground Load Haul Dump (LHD) vehicles. Top graph: primary trap; middle graph: filter; bottom graph: secondary trap

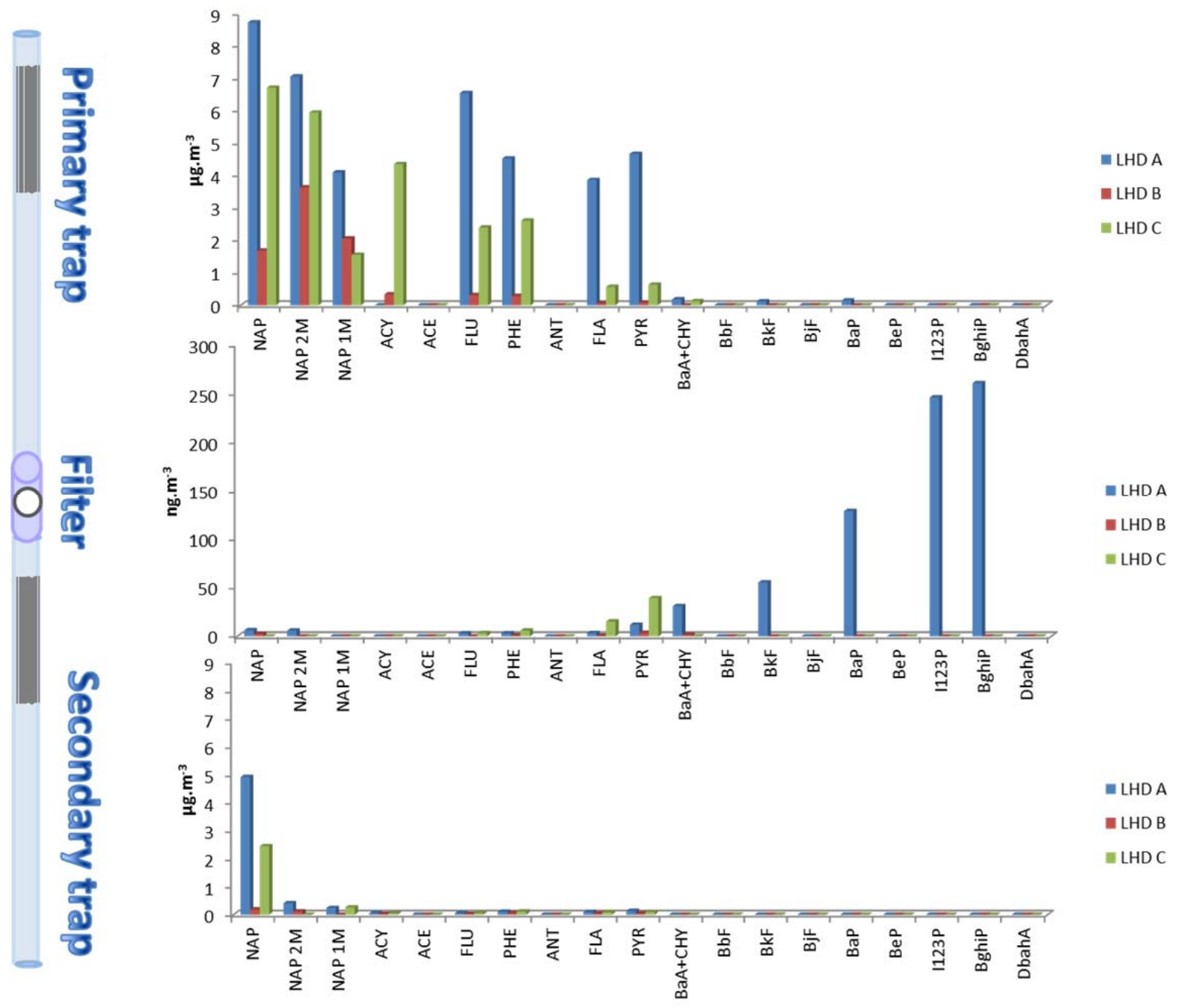


$760 \mathrm{ng} \mathrm{m}^{-3}$ per sample, whilst the total gas phase PAHs detected ranged from 1.1 to $40 \mu \mathrm{g} \mathrm{m}^{-3}$ per sample (primary trap concentrations). No relationship between ambient sampling temperature and gas/particle PAH partitioning was found, which indicated that this effect was negligible over this temperature range. The difference in PAH concentrations between the gas and particle phases we found are to be expected, as emission rates for a vehicle fleet in a tunnel were found to be $390.5 \mathrm{~g} \mathrm{~L}^{-1}$ (mass per litre of fuel consumed) in the vapour phase versus $3.6 \mu \mathrm{g} \mathrm{L}^{-1}$ for fluoranthene and $512.3 \mu \mathrm{g} \mathrm{L}^{-1}$ and $6.2 \mu \mathrm{g} \mathrm{L}^{-1}$ for pyrene, respectively [28]. Gas-particle partitioning of PAHs is a complex process and depends on numerous variables [29]. Mostly PAHs of volatility lower than and equal to pyrene could be quantified on the primary traps (Table 4), and overall the highest PAH concentration in the gas phase was for naphthalene which ranged from 0.15 to $18 \mu \mathrm{g} \mathrm{m}^{-3}$. With the exception of the Plat mine B nondiesel sample which contained the highest individual concentration of $18 \mu \mathrm{g} \mathrm{m}^{-3}$ for naphthalene, the highest gas phase naphthalene concentrations were found in the LHD samples. PAHs from acenaphthylene to pyrene were generally present at concentrations $<1.00 \mu \mathrm{g} \mathrm{m}^{-3}$ for each sample except for the LHD exhaust samples, where higher values were determined. For example, the gas phase PAHs in the Plat mine A LHD sample ranged from 3.9 to $8.7 \mu \mathrm{g} \mathrm{m}^{-3}$ for the more volatile 2-4 ringed PAHs and 0.12 to $0.18 \mu \mathrm{g} \mathrm{m}^{-3}$ for the heavier 5-6 ringed PAHs that were detected in this sample.

Table 4 revealed that the concentration of analytes that were found on the filters were orders of magnitude smaller than the concentrations found on the trap samples and were in the $\mathrm{ng} \mathrm{m}^{-3}$ range. This confirms the importance of sampling both gas and particle phases when determining human exposure levels to PAHs. Fluorene and phenanthrene were found to range from 0.47 to $9.7 \mathrm{ng} \mathrm{m}^{-3}$ on the filters, whereas fluoranthene and pyrene were found to have higher concentrations from 0.52 to $110 \mathrm{ng} \mathrm{m}^{-3}$. These four PAHs were commonly seen in the filter samples and pyrene had the highest concentrations in most samples. The common occurrence of pyrene at appreciable concentrations in filter samples suggests that it may serve as a useful indicator of PAH exposure in underground mining environments. This may be feasible, as currently filter samples are collected for the determination of underground worker exposure to diesel particulate matter, therefore a simplified analytical method to screen for pyrene in punched portions from these filters could be developed. The Plat mine $C$ workshop sample contained the highest concentration for particle associated pyrene of $110 \mathrm{ng} \mathrm{m}^{-3}$. Comparatively high concentrations were also found for the heavier PAHs in this workshop sample which resembled the LHD Plat mine A sample. This is likely due to the high number of diesel vehicles present in the workshop whilst sampling, or as a consequence of non-optimal ventilation in this area.

With respect to the filter samples, the highest individual PAH concentrations overall were for the heavier PAHs, specifically benzo[a]pyrene, indeno[1,2,3-cd]perylene and benzo[ghi]perylene in the Plat mine A LHD sample. This sample also contained the largest number of particle phase PAHs with a concentration range from 3.1 to $260 \mathrm{ng} \mathrm{m}^{-3}$. In contrast, the Plat mine B LHD sample contained far fewer particle associated PAHs at relatively low concentrations, with a pyrene concentration of $3.6 \mathrm{ng} \mathrm{m}^{-3}$ being the maximum.

The LHD sample from Plat mine A revealed the highest total PAH concentration in both the gas and particle phases with corresponding values of $40 \mu \mathrm{g} \mathrm{m}^{-3}$ and $760 \mathrm{ng} \mathrm{m}^{-3}$ likely reflecting the cold start vehicle emission conditions, as previously mentioned.

The dominant PAHs found in the gas and particle phases in this study agree with literature with respect to PAHs in diesel emissions in other environments where filters and PUF/XAD-4 sampling was employed [3], which indicates the efficiency of our denuder in partitioning 
sampling applications for PAHs. The comparatively higher concentrations of PAHs in the gas phase proved the importance of sampling both phases in order to elucidate human exposure, as sampling only the particle phase, which is the current practice, may be an underestimation, especially in light of the fact that heavier PAHs were present in the gas phase in some cases (refer to Table 4). Even though the lower molecular mass PAHs (which are the main gas phase components) have lower Toxicity Equivalency Factors (TEFs) than the heavier PAHs (naphthalene and pyrene have TEFs of 0.001 , whilst benzo[a]pyrene has a TEF of 1 , for example) [30], the gas phase concentrations were in the $\mu \mathrm{g} \mathrm{m}^{-3}$ range, whilst the particle phase $\mathrm{PAHs}$ were in the $\mathrm{ng} \mathrm{m}^{-3}$ range, therefore the low molecular mass PAHs may contribute significantly to the overall toxicity in some cases.

\subsection{Diagnostic ratios}

The diversity of $\mathrm{PAH}$ sources can be characterized by diagnostic ratios where the concentration of specific PAH compounds, or groups of PAHs, have been used to identify different emission sources [31], [32], [33]. In this study, diagnostic ratios were an important means to determine whether airborne PAHs in the underground mines originated from the emissions of underground diesel engines or from other sources, particularly from the ambient air intake. The intake air vents are located above ground in semi-rural environments. There was thus a possibility that the intake air could contain PAHs arising from biomass burning ("veld" fires) or domestic fuel combustion in the surrounding informal settlements.

Diagnostic ratios were therefore calculated for total PAHs (primary trap samples+filter samples+secondary trap samples) which would account for both the gas and particle phases (Table 5). The ratios were generally different for the non-diesel shafts, particularly with respect to the $\mathrm{FLA} /(\mathrm{FLA}+\mathrm{PYR})$ and $\mathrm{ANT} /(\mathrm{ANT}+\mathrm{PHE})$ ratios, which may indicate different sources of PAHs in these environments. A FLA/PYR ratio of approximately 0.6 for a number of diesel shaft samples confirms vehicular emissions as a source and when used in conjunction with the $\mathrm{FL} /(\mathrm{FL}+\mathrm{PYR})$ ratio, which was in most cases $>0.5$, indicates that diesel vehicular emissions were a dominant source of $\mathrm{PAH}$ emissions in the underground diesel shafts.

\subsection{Principal component analysis}

PCA was performed to compare the 10 min ambient and LHD exhaust sample results, which have sampling time and sample volume in common (Fig. 8). It was found that the first principal component accounted for $75.3 \%$ of the explained variance between ambient and LHD samples. The scores plot showed that there was very good grouping of samples with respect to the different sampling media (Fig. 8: primary trap (P), filter (F) and secondary trap (S) represented by different colours). The sample type did not show grouping patterns as they were sporadically distributed within the groups of the different colours, which was to be expected as the LHDs were the main source of PAHs in the ambient sampling environment. The loadings plot clearly revealed the PAHs which contributed to the differences between the sampling media: heavier PAHs for the filter samples, with only the most volatile PAHs (namely azulene and naphthalene) contributing to the secondary trap variance. Therefore it can be concluded that samples can be grouped according to the sampling medium, which confirms the efficacy of the denuder with respect to the sampling of different phase PAHs, however they could not be grouped effectively 
Figure 8: Principal component analysis scores plot (left) and loadings plot (right) for the $10 \mathrm{~min}$ ambient and Load Haul Dump (LHD) sample results from three different mines (primary trap $(\mathrm{P})$; filter $(\mathrm{F})$ and secondary trap $(\mathrm{S})$ )
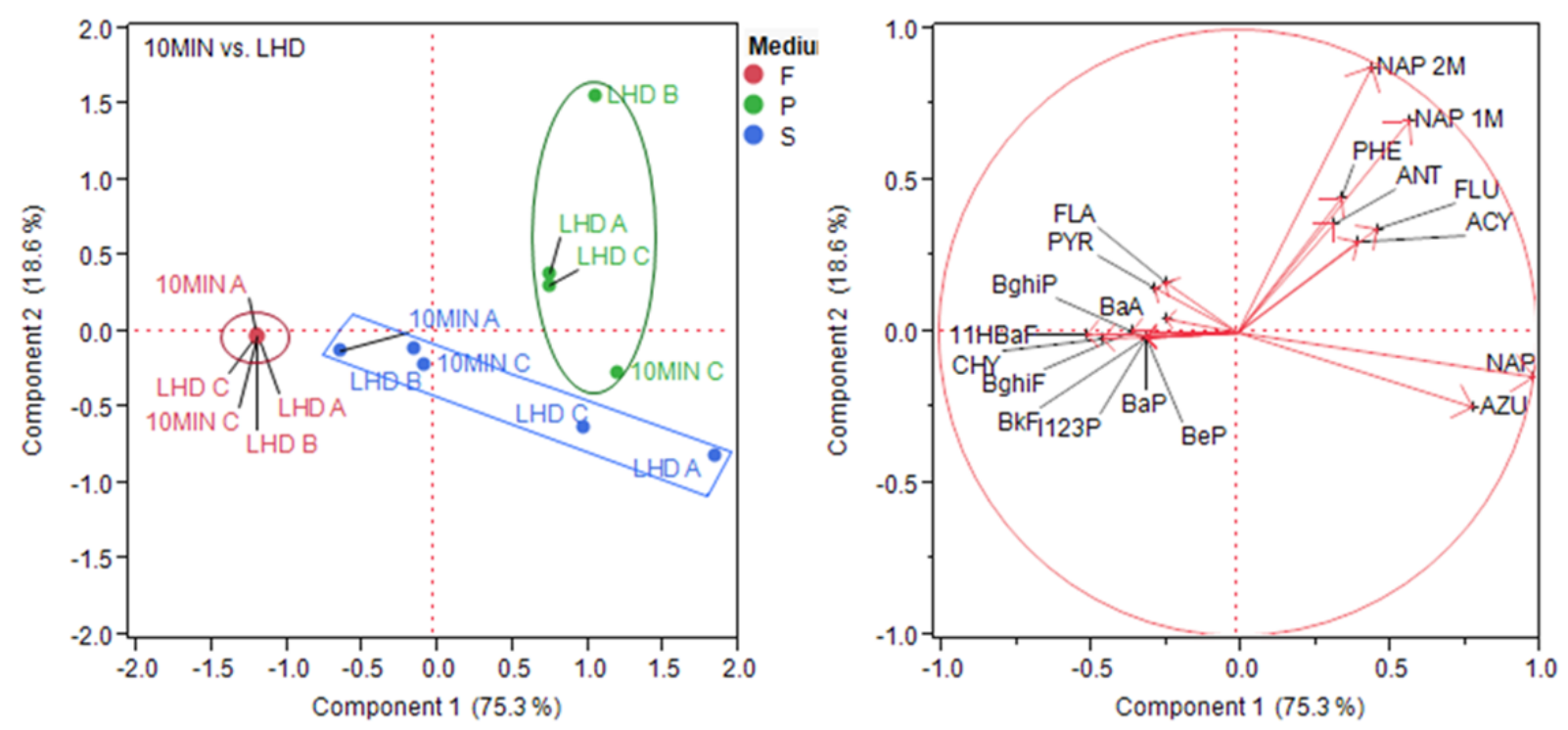
Table 5: Diagnostic ratios of PAHs found in the underground mine samples, based on total $\mathrm{PAH}$ content (gas and particle phases)

\begin{tabular}{|c|c|c|c|c|c|}
\hline & $\begin{array}{c}\mathrm{FL} /(\mathrm{FL}+\mathrm{PYR}) \\
{[32]}\end{array}$ & $\begin{array}{c}\mathrm{FLA} /(\mathrm{FLA}+\mathrm{PYR}) \\
{[34]}\end{array}$ & $\begin{array}{c}\text { ANT/(ANT+PHE) } \\
{[35]}\end{array}$ & $\begin{array}{c}\Sigma \mathrm{LMW} / \Sigma \mathrm{HMW} \\
{[36]}\end{array}$ & $\begin{array}{c}\text { FLA/PYR } \\
\text { [31] }\end{array}$ \\
\hline 30MIN A & 0.5 & 0.23 & 0.1 & 6.3 & 0.3 \\
\hline 30MIN B & 0.3 & 0.33 & 0.1 & 15 & 0.5 \\
\hline 30MIN C & 0.6 & 0.22 & 0.1 & 14 & 0.3 \\
\hline WS A & 0.9 & 0.35 & 0.1 & 290 & 0.5 \\
\hline WS B & 1.0 & 0.0 & 0.1 & 740 & 0.0 \\
\hline WS C & 0.4 & 0.28 & 0.1 & 2.0 & 0.4 \\
\hline LHD A & 0.6 & 0.39 & 0.1 & 5.5 & 0.7 \\
\hline LHD B & 0.6 & 0.27 & 0.0 & 24 & 0.4 \\
\hline LHD C & 0.5 & 0.33 & 0.1 & 10 & 0.5 \\
\hline 10MIN C & 0.9 & 0.87 & 0.0 & 12 & 6.8 \\
\hline ND A & 0.8 & 0.46 & 0.0 & 210 & 0.8 \\
\hline ND B & 0.9 & 0.50 & 0.0 & 19000 & 1.0 \\
\hline Sources & $\begin{array}{c}\text { Diesel } \\
\text { emissions } \\
(>0.5) \\
\text { Petrol } \\
\text { emissions } \\
(<0.5)\end{array}$ & $\begin{array}{c}\text { Fossil fuel } \\
\text { combustion } \\
(0.4-0.5) \\
\text { Coal and wood } \\
\text { combustion }(>0.5) \\
\text { Petrogenic }(<0.4)\end{array}$ & $\begin{array}{c}\text { Pyrogenic } \\
(>0.1) \\
\text { Petrogenic } \\
(<0.1)\end{array}$ & $\begin{array}{c}\text { Pyrogenic } \\
(<1) \\
\text { Petrogenic } \\
(>1)\end{array}$ & $\begin{array}{c}\text { Vehicles } \\
(\sim 0.6)\end{array}$ \\
\hline
\end{tabular}

$\Sigma$ LMW -sum of the low molecular weight PAHs (2-3 rings)

$\Sigma \mathrm{HMW}$-sum of the higher molecular weight PAHs (4-5 rings) 
according to the sample type in this case, which indicates a common source of PAHs in these diesel shaft samples.

\section{Conclusions}

$\mathrm{PAHs}$ are present in the atmosphere in both the gas and particle phases, each of which has different potential human health impacts as a consequence of the fate of the PAHs in the human body. It was for this reason that the PAHs in both phases were simultaneously sampled in underground mining environments, which was made possible for the first time by utilizing the denuder sampling devices reported here. The denuders were easily prepared in the laboratory with little cost and were convenient to use and transport as they are small, lightweight and portable. They also only require a small, portable personal sampling pump for air sampling. These pumps are intrinsically safe, which is an important consideration in the underground mining environment. The effective trapping of the PAHs in both gas and particle phases was made evident in this study and the results were consistent with denuder theory and allowed us to report on the simultaneous concentrations of gas and particle phase PAHs in the atmosphere of underground platinum mines in South Africa for the first time. This is a challenging sampling environment, due to space and utility constraints, as well as safety issues, which prevent the use of equipment which may pose a fire ignition risk.

PAHs that were detected in the mines studied ranged from 2- ringed gas phase PAHs that were found on the trap samples to 5-6 ringed particle associated PAHs which were detected on the filter samples. PAHs were predominantly found to exist in the gas phase with naphthalene and its mono- methylated derivatives being the most abundant. This emphasises the need for gas phase sampling as the current practice of only sampling the particle phase would lead to an underestimation of potential occupational exposure to PAHs. Pyrene was the most abundant particle associated $\mathrm{PAH}$, therefore this compound may serve as a useful indicator of $\mathrm{PAH}$ exposure in mining environments. Samples taken at the exhaust of underground diesel vehicles were found to have the highest concentrations of PAHs in both phases and included heavier $\mathrm{PAHs}$ such as benzo[k]fluoranthene, benzo[a]pyrene, indeno[1,2,3-cd]pyrene and benzo[ghi]perylene.

The three mines which were investigated were found to have varying concentrations of PAHs which can be attributed to the fact that the instantaneous environments whilst sampling were different at each mine with respect to possible emission sources that were observed, which is the main difficulty with comparative monitoring in this environment. This initial scoping study has, however, shown the potential for this method of monitoring PAHs in challenging underground environments, and it is recommended that additional sampling campaigns be undertaken to enable the method to be further investigated and validated, which in turn may allow for its more routine use.

\section{Acknowledgements}

Resources provided by Leco Africa and Restek (USA) are gratefully acknowledged. Thanks to the CSIR, Centre for Mining Innovation, particularly Cecilia Pretorius. Funding provided by the NRF and SASOL is acknowledged, as is Impala Platinum for granting Genna-Leigh Geldenhuys 
study leave and funding in order for her to complete her MSc. The Plat Mines are gratefully acknowledged for funding and guided underground sampling visits.

\section{References}

[1] M. Ono-Ogasawara, T.J. Smith, Diesel exhaust particles in the work environment and their analysis, Ind. Health 42 (4) (2004) 389-399.

[2] E. Borrás, L.A. Tortajada-Genaro, M. Vázquez, B. Zielinska, Polycyclic aromatic hydrocarbon exhaust emissions from different reformulated diesel fuels and engine operating conditions, Atmos. Environ. 43 (2009) 5944-5952.

[3] K.F. Ho, S.S.H. Ho, S.C. Lee, Y. Cheng, J.C. Chow, J.G. Watson, P.K.K. Louie, L. Tian, Emissions of gas- and particle-phase polycyclic aromatic hydrocarbons (PAHs) in the Shing Mun Tunnel, Hong Kong, Atmos. Environ. 43 (40) (2009) 6343-6351.

[4] Chamber of Mines of South Africa. Annual report 2012/2013 (2012).

[5] R.J. Laumbach, H.M. Kipen, Respiratory health effects of air pollution: Update on biomass smoke and traffic pollution, J. Allergy Clin. Immunol. 129 (2012) 3-11.

[6] IARC (International Agency for Research on Cancer), Diesel engine exhaust carcinogenic (2012) Press Release no. 213.

[7] B. Temime-Roussel, A. Monod, C. Massiani, H. Wortham, Evaluation of an annular denuder tubes for atmospheric PAH partitioning studies - 1: Evaluation of the trapping efficiency of gaseous PAHS, Atmos. Environ. 38 (13) (2004) 1913-1924.

[8] A. Fushimi, S. Hashimoto, T. leda, N. Ochiai, Y. Takazawa, Y. Fujitani, K. Tanabe, Thermal desorption - comprehensive two-dimensional gas chromatography coupled with tandem mass spectrometry for determination of trace polycyclic aromatic hydrocarbons and their derivatives, J. Chromatogr. A 1252 (2012) 164-170.

[9] F. Mercier, P. Glorennec, O. Blanchard, B. Le Bot, Analysis of semi-volatile organic compounds in indoor suspended particulate matter by thermal desorption coupled with gas chromatography/mass spectrometry, J. Chromatogr. A. 1254 (2012) 107-114.

[10] J. Gil-Moltó, M. Varea, N. Galindo, J. Crespo, Application of an automatic thermal desorption-gas chromatography-mass spectrometry system for the analysis of polycyclic aromatic hydrocarbons in airborne particulate matter, J. Chromatogr. A 1216 (2009) 12851289.

[11] L-B. Liu, Y. Liu, J-M. Lin, N. Tang, K. Hayakawa, T. Maeda, Development of analytical methods for polycyclic aromatic hydrocarbons (PAHs) in airborne particulates: A review, J. Env. Sci. 19 (2007) 1-11.

[12] S.K. Pandey, K-H., Kim, R.J.C. Brown, A review of techniques for the determination of polycyclic aromatic hydrocarbons in air, TrAC 30 (11) (2011) 1716-1739. 
[13] A. Eiguren-Fernandez, A.H. Miguel, J.R. Froines, S. Thurairatnam, E.L. Avol, Seasonal and spatial variation of polycyclic aromatic hydrocarbons in vapor-phase and PM2.5 in southern California urban and rural communities, Aerosol Sci.Technol. 38 (5) (2004) 447-455.

[14] D.J. Eatough, A. Wadsworth, D.A. Eatough, J.W. Crawford, L.D. Hansen, E.A. Lewis, A multiple-system, multichannel diffusion denuder sampler for the determination of fineparticulate organic material in the atmosphere, Atmos. Environ. Part A 27 (8) (1993) 12131219.

[15] M. Possanzini, V. Di Palo, P. Gigliucci, M.C. Tomasi Scianò, A. Cecinato, Determination of phase-distributed PAH in Rome ambient air by denuder/GC-MS method, Atmos. Environ. 38 (12) (2004) 1727-1734.

[16] L.A. Gundel, V.C. Lee, K.R.R. Mahanama, R.K. Stevens, J.M. Daisey, Direct determination of the phase distributions of semi-volatile polycyclic aromatic hydrocarbons using annular denuders, Atmos. Environ. 29 (14) (1995) 1719-1733.

[17] B. Temime, S. Francois, A. Monod, H. Wortham, An experimental set up of a PAH vapour generator and its use to test an annular denuder, Environ. Pollut. 120 (3) (2002) 609-616.

[18] R.W. Coutant, P.J. Callahan, M.R. Kuhlman, R.G. Lewis, Design and performance of a high-volume compound annular denuder, Atmos. Environ. 23 (1989) 2205-2211.

[19] R.W. Coutant, P.J. Callahan, J.C. Chuang, R.G. Lewis, Efficiency of silicone-grease-coated denuders for collection of polynuclear aromatic hydrocarbons, Atmos. Environ. Part A 26(15) (1992) 2831-2834.

[20] P.B.C. Forbes, E.W. Karg, R. Zimmermann, E.R. Rohwer, The use of multi-channel silicone rubber traps as denuders for polycyclic aromatic hydrocarbons, Anal. Chim. Acta 730 (2012) 71-79.

[21] P.B.C. Forbes, Particle emissions from household fires in South Africa, Air Pollution Conference, 16-18 May 2012, La Coruna, Spain. Published in Air Pollution XX, WIT Transactions on Ecology and the Environment 157 (2012) 445-456 ISSN 1743-3541.

[22] E.K. Ortner, E.R. Rohwer, Trace analysis of semi-volatile organic air pollutants using thick film silicone rubber traps with capillary gas chromatography, J. High Resolut. Chromatogr. 19 (1996) 339-344.

[23] J. de Vos, P. Gorst-Allman, E. Rohwer, Establishing an alternative method for the quantitative analysis of polychlorinated dibenzo-p-dioxins and polychlorinated dibenzofurans by comprehensive two dimensional gas chromatography-time-of-flight mass spectrometry for developing countries, J. Chromatogr. A 1218 (21) (2011) 3282-3290.

[24] E. Baltussen, F. David, P. Sandra, H.-G. Janssen, C.A. Cramers, Sorption tubes packed with polydimethylsiloxane: a new and promising technique for the preconcentration of volatiles and semi-volatiles from air and gaseous samples, J. High Resol. Chromatogr. 21 (1998) 332340. 
[25] R.J. Lavrich, M.D. Hays, Validation studies of thermal extraction-GC/MS applied to source emissions aerosols. 1. Semivolatile analyte-nonvolatile matrix interactions, Anal. Chem. 79 (2007) 3635-3645.

[26] M. Tsapakis, E.G. Stephanou, Occurrence of gaseous and particulate polycyclic aromatic hydrocarbons in the urban atmosphere: study of sources and ambient temperature effect on the gas/particle concentration and distribution, Environ. Pollut. 133 (2005) 147-156.

[27] P.B.C. Forbes, E.R. Rohwer, Investigations into a novel method for atmospheric polycyclic aromatic hydrocarbon monitoring, Environ. Pollut. 157 (8-9) (2009) 2529-2535.

[28] M.P. Fraser, G.R. Cass, B.R.T. Simoneit, Gas-phase and particle-phase organic compounds emitted from motor vehicle traffic in a Los Angeles roadway tunnel, Environ. Sci. Technol. 32 (1998) 2051-2060.

[29] J. Dachs, S.J. Eisenreich, Adsorption onto aerosol soot carbon dominates gas-particle partitioning of polycyclic aromatic hydrocarbons, Environ. Sci. Technol. 34 (2000) 3690-3697.

[30 I.C.T. Nisbet, P.K. LaGoy, Toxic equivalency factors (TEFs) for polycyclic aromatic hydrocarbons (PAHs), Regul. Toxicol. Pharm. 16 (1992) 290-300.

[31] K. Ravindra, R. Sokhi, R. Van Grieken, Atmospheric polycyclic aromatic hydrocarbons: Source attribution, emission factors and regulation, Atmos. Environ. 42 (13) (2008) 28952921.

[32] K. Ravindra, E. Wauters, R. Van Grieken, Variation in particulate PAHs levels and their relation with the transboundary movement of the air masses, Sci. Total Environ. 396 (2-3) (2008) 100-110.

[33] M. Tobiszewski, J. Namieśnik, PAH diagnostic ratios for the identification of pollution emission sources, Environ. Pollut. 162 (2012) 110-119.

[34] R.J. De La Torre-Roche, W. Lee, S.I. Campos-Díaz, Soil-borne polycyclic aromatic hydrocarbons in El Paso, Texas: Analysis of a potential problem in the United States/Mexico border region, J. of Hazard. Mater. 163 (2-3) (2009) 946-958.

[35] C. Pies, B. Hoffmann, J. Petrowsky, Y. Yang, T.A. Ternes, T. Hofmann, Characterization and source identification of polycyclic aromatic hydrocarbons (PAHs) in river bank soils, Chemosphere 72 (10) (2008) 1594-1601.

[36] W. Zhang, S. Zhang, C. Wan, D. Yue, Y. Ye, X. Wang, Source diagnostics of polycyclic aromatic hydrocarbons in urban road runoff, dust, rain and canopy throughfall, Environ. Pollut. 153 (3) (2008) 594-601. 